\title{
Agôn
}

Revue des arts de la scène

Critiques | Saison 2010-2011

\section{Le Dindon de Feydeau mis en scène par Philippe Adrien}

Alice Carré

\section{OpenEdition}

Journals

Édition électronique

URL : http://journals.openedition.org/agon/1232

DOI : $10.4000 /$ agon. 1232

ISSN : 1961-8581

\section{Éditeur}

Association Agôn

Référence électronique

Alice Carré, «Le Dindon de Feydeau mis en scène par Philippe Adrien », Agôn [En ligne], Critiques, mis en ligne le 17 octobre 2010, consulté le 23 septembre 2020. URL : http://journals.openedition.org/ agon/1232 ; DOI : https://doi.org/10.4000/agon.1232

Ce document a été généré automatiquement le 23 septembre 2020

Association Agôn et les auteurs des articles 


\title{
Le Dindon de Feydeau mis en scène par Philippe Adrien
}

\author{
Alice Carré
}

Pour la première fois de sa carrière, Philippe Adrien monte Feydeau. Le vaudeville, qui ne l'avait jamais attiré auparavant, semble trouver une résonance particulière avec son univers esthétique. La mise en scène donne tout son relief à la redoutable efficacité dramatique du texte, mais derrière la folie des situations se profile une lecture de l'inconscient des personnages, engoncés dans leurs principes et ravagés de désirs. Créateur d'images oniriques saisissantes, le metteur en scène ponctue son orchestration précise de la pièce de Feydeau par des instants de cauchemar et des accents absurdes qui extirpent la pièce de son réalisme. 
Le Dindon, de Georges Feydeau mis en scène par Philippe Adrien

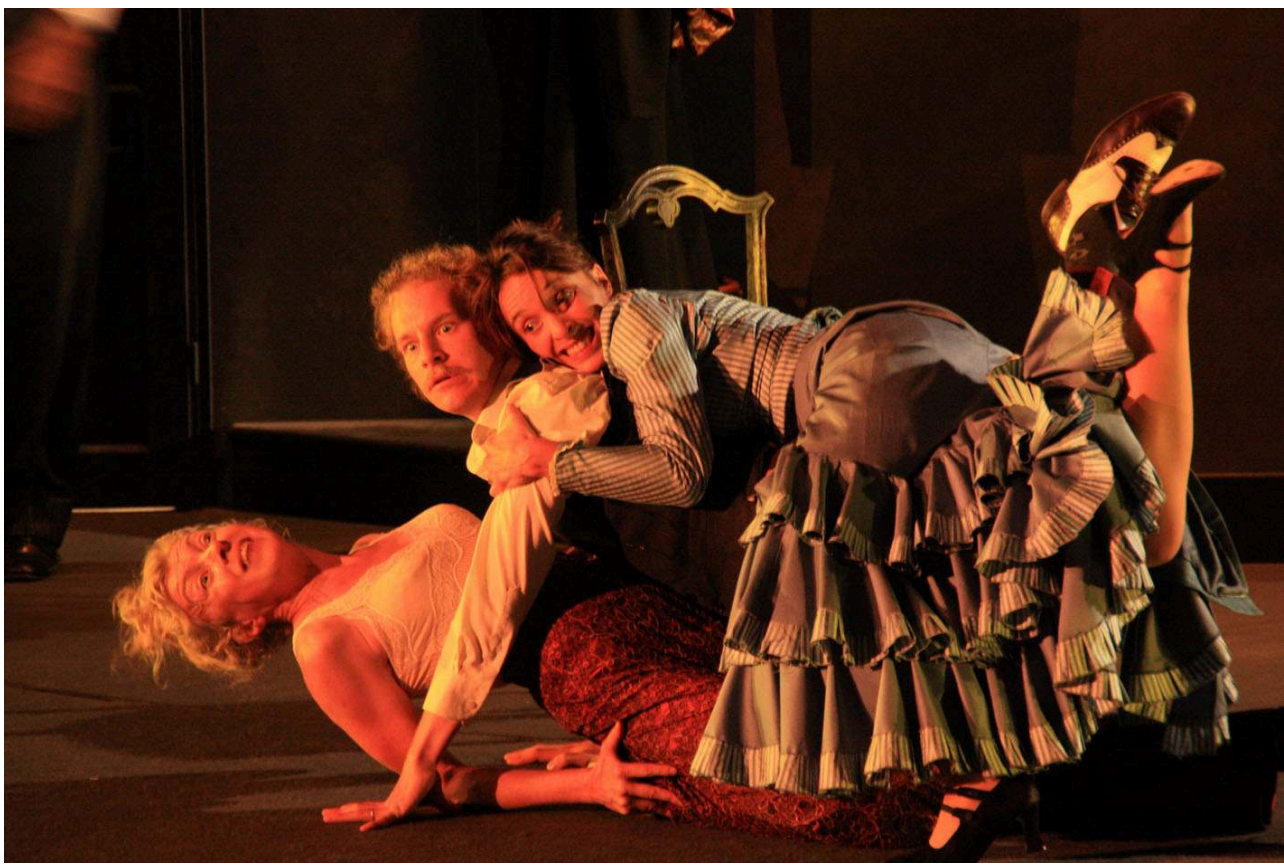

(c) Antonia Bozzi

2 Autrefois méprisé pour sa plume facile et frivole, Feydeau est aujourd'hui considéré comme un génie de l'écriture comique. Sa reconnaissance est manifeste avec la publication en 1956 d'une édition du Théâtre complet où Marcel Achard hissait Feydeau au rang de "plus grand auteur comique français » après Molière ${ }^{1}$. Depuis les mises en scène de l'époque des célèbres boulevards, où les portes claquaient au sein d'une bonbonnière aux mille trappes et placards, l'intérêt des metteurs en scène semble s'être déplacé. La célèbre « mécanique » des intrigues de Feydeau fascine toujours, mais on traite volontiers l'auteur comme un précurseur de l'absurde, comme une œuvre qui, par l'humour, met en place un soigneux et irréversible dérèglement du réel. L'enchaînement des situations alambiquées est davantage apprécié pour sa manière de superposer au comique le cauchemar et l'inquiétude. Ce qui intéresse aujourd'hui les metteurs en scène, c'est le défilé des inconscients débridés et livrés à eux-mêmes, la folie humaine qui signe la faillite des codes sociaux de la bourgeoisie. Une lecture kafkaïenne dominait, la saison dernière, la mise en scène de L'Affaire de la rue Lourcine de Labiche réalisée par Daniel Jeanneteau et Marie-Christine Soma. Des costumes boursoufflés réduisaient les personnages à de pures émanations de fantasmes, à des corps obscènes, déformés par les pulsions. Engloutis dans un univers inquiétant, chacun se livre sans aucun contrôle à ses élans instinctifs et primaires.

Philippe Adrien traite plus légèrement cette mise en œuvre de l'inconscient des personnages, ne renonçant pas à une mise en place plus conventionnelle de l'intrigue, à des costumes d'époque et des éléments de décor réalistes. Le premier dérèglement qu'il fait subir au cadre réaliste émane d'une interprétation très charnelle et physique des acteurs. Sur le plateau se déploie une véritable dynamique des corps et une visibilité du désir. Les êtres sont souples, agiles, toujours en quête de plaisir, les gestes font le contraire de ce qu'énonce la raison. L'attirance transpire alors qu'on jure ne pas s'y laisser prendre, les corps ne cessent d'entrer en friction quand ils disent garder leurs distances. 
Le Dindon, de Georges Feydeau mis en scène par Philippe Adrien

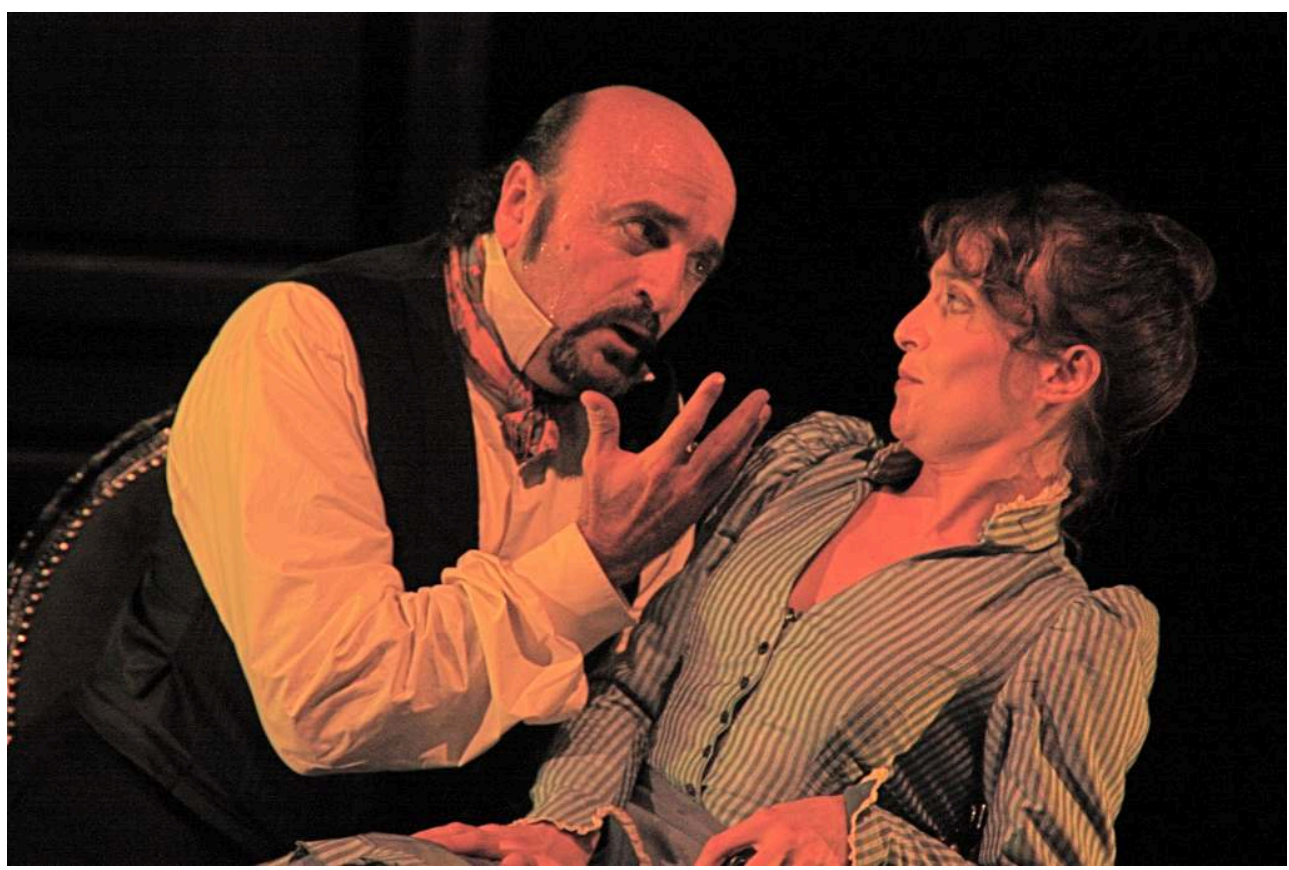

(c) Antonia Bozzi

4 Paradoxalement peut-être, la distribution fonctionne à merveille grâce à des interprétations très diverses et toutes singulières. Le jeu d'Eddie Chignara, en Pontagnac, matador de l'amour qui poursuit de ses assiduités une femme mariée, exubérant et excessif, est tempéré par la proposition très juste et sans excès d'Alix Poisson (Madame Vatelin). À leurs côtés, des compositions hautes en couleurs, telle que celle de Caroline Arrouas, qui campe une Maggy Soldignac hystérique et diablement british, donnent le change à des interprétations plus discrètes, comme celle de PierreAlain Chapuis en mari presque honnête et dépassé.

5 Appliquant un précepte d'Eugène Labiche : "Une pièce est une bête à mille pattes qui doit toujours être en route. Si elle ralentit, le public bâille; si elle s'arrête, il siffle $»^{2}$, les acteurs donnent à la représentation un rythme soutenu qui va crescendo. Le mouvement semble être au cœur de la dramaturgie du spectacle à travers cascades, ratages, cavalcades éperdues, à tel point qu'il est esthétisé pour lui-même. Une scène de course et de désir est comme figée par le déclenchement d'un stroboscope dont la lumière intermittente crée un effet de sidération. C'est bien l'accélération qui caractérise l'explosion d'un désir trop longtemps contenu et réprimé. Conscient aussi que le ralentissement pourra exprimer pleinement le trouble dans lequel les situations plongent les personnages, le metteur en scène concocte une scène à lecture ralentie, où le respectable $M$. Soldignac apparaît avec un costume de lapin et parle de sa voix amplifiée par des micros déformants. Ce passage se resserre sur la perception ahurie du mari, M. Vatelin, dont l'esprit logique est désarçonné et ne perçoit plus les événements qu'à travers un magma confus.

6 Ces procédés rythmiques empruntent parfois leur technique au cinéma. Le plateau tournant retenu pour la scénographie permet d'user de l'effet du travelling, et de représenter la poursuite angoissante d'un mâle prédateur s'acharnant à épier et suivre une jeune femme alors qu'elle rentre chez elle. Il apparaît alors derrière une porte, une 
fenêtre, dans l'ombre d'un réverbère, jouant du mouvement du plateau. Ce plateau prend au pied de la lettre la métaphore du rouage et de la machine associées à la dramaturgie de Feydeau et permet d'accentuer la dynamique de la construction du texte. Le dispositif donne également aux espaces réalistes une profondeur de champ qui ouvre sur un espace inconnu. S'il peut évoquer le dédale de cachettes et de recoins si chers au genre, il sert surtout à créer de l'invisible, à ouvrir sur un au-delà suggérant l'obscurité des zones psychiques les plus reculées.

\section{NOTES}

1. Voir l'introduction de Henry Gidel dans Le théâtre de Georges Feydeau, éd. Klinchsieck, 1979, Paris.

2. Propos reproduits par A. Carel, Eugène Labiche, Paris, 1885, p. 70.

INDEX

Mots-clés : Adrien (Philippe), Feydeau (Georges), Le Dindon 